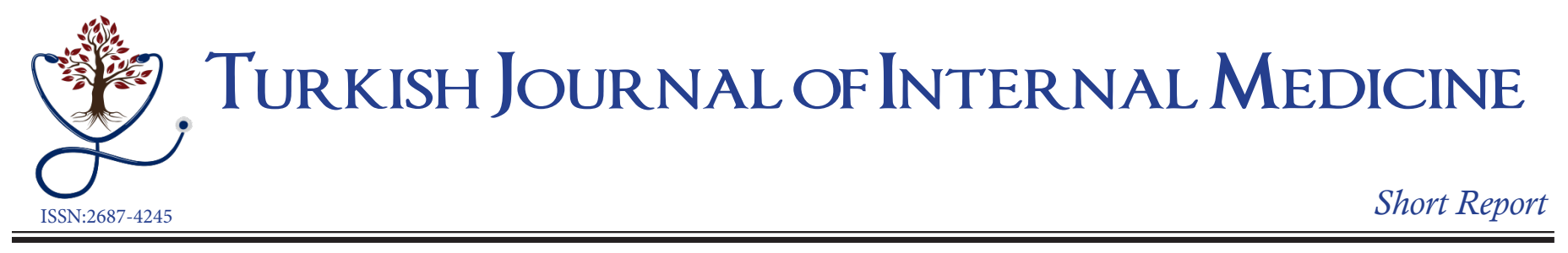

\title{
General characteristics of the patients diagnosed with Enteropathic arthritis (ENA) whose treatment have been performed with biological agents
}

\author{
Nihal LERMİ ${ }^{1}$, Yavuz PEHLIVAN ${ }^{1}$ \\ ${ }^{1}$ Bursa Uludağ University Faculty of Medicine, Department of Internal Medicine, Division of Rheumatology, Bursa, Turkey
}

Turk J Int Med 2021;3(Supplement 1):S38-S39

DOI: $10.46310 /$ tjim.876957

Keywords: Enteropathic arthritis, clinical features, spondylarthritis, Biological treatment

Spondylarthritis (SpA) comprises multiple divergent forms of inflammatory arthritis. It has got extraarticular symptoms like uveitis, psoriasis and inflammatory bowel diseases (IBD). Enteropathic arthritis (ENA) (in another naming, arthritis due to IBD ranks in SpA group because of the similarity of clinical features and the common genetic susceptibility as well. The term of ENA is used for the patients who has ulcerative colitis or Chron's disease and developed inflammatory arthritis as well. ${ }^{1}$ The most frequent extraintestinal symptom in the individuals with IBD is the articular ones. The frequency of SpA in IBD patients is $28.7 \%$. $^{2}$ The male/female ratio among ENA patients' uniform. Peripherial joint involvement or axial spine contagion have been reported in $17-39 \%$ of the IBD patients. Sometimes arthritis might originate before the diagnosis of IBD. $^{2}$ Non-steroidal anti-inflammatory drugs (NSAID's), corticosteroids, sulfasalazine, antiTNF agents can be used in the treatment of the patients with axial or peripheral involvement. In this study, we aimed to present the features of 33
ENA cases that have been being monitored in our center.

Demographical and clinical features, presentation forms, family histories, smoking habits, HLA-B27 positivity of the 33 ENA cases who sought medical service in our outpatient clinic and were diagnosed with ENA and treated with biological agents have been recorded. Their peripheric arthritis, dactylitis, enthesitis, uveitis, and psoriasis stories have been picked. It has been interrogated before biological agents treatment whether conventional DMARD's (diseasemodifying antirheumatic drugs) were used.

Sixteen of the patients $(48.4 \%)$ have been females, whereas 17 of them $(51.6 \%)$ have been males. Eleven of the patients (33.3\%) have been diagnosed with Chron's disease, whereas 22 of them $(66.7 \%)$ with ulcerative colitis. Eighteen patients (54.5\%) have presented with joint complaints, 13 of them (39.4\%) with bowel complaints, and 1 of them $(3 \%)$ has presented with simultaneous joint and bowel complaints. Families of the 2 of the 18 patients $(6.1 \%)$ whose family stories could have

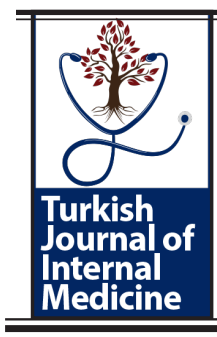

Received:February 08, 2021;Accepted:March 5, 2021; Published Online:March 6, 2021

Address for Correspondence:

Nihal LERMI

Bursa Uludağ University Faculty of Medicine, Department of Internal Medicine, Division of

Rheumatology, Bursa, Turkey

E-mail:nihalyilmaz16@hotmail.com 
been achieved had rheumatic disease background. Fourteen of the 26 patients (42.4\%) whose smoking characteristics could have been identified, have been active smokers. HLA-B27 of the 12 patients (36.4\%) have been positive. Sacroiliitis have been identified in the graphics of the 26 patients (78.8\%). Thirty-four patients (93.9\%) had axial skeleton involvement whereas 11 of them $(24.2 \%)$ had joint involvement. Eight of the patients (24.2\%) had peripheric arthritis, 2 of them (6.1\%) had enthesitis, 6 of them (18.2\%) had heel pain. The inquiry of the pre-treatments before the biological agents among the patients whose data could have been achieved presented that 6 of them (18.2\%) used methotrexate, 16 of them (48.5\%) used steroids, 16 of them (48.5\%) used azathioprine, 16 of them (48.5\%) salazopyrin, 23 of them (69.7\%) used NSAID's. Seventeen of the patients (51.5\%) have used NSAID's after IBD diagnosis whereas 4 patients (12.1\%) had IBD inflammation symptoms as bleeding and diarrhea due to NSAID's use after IBD diagnosis.

Since there is a close link between SpA and ENA, patients should also be monitored in the aspect of bowel symptoms during the SpA course. Even if it is rare, the initial seeking way of the patients with IBD might be joint complaints. Hence joint complaints must be taken into consideration. Early diagnosis is substantial with regards to treatment options. It is needed to take into account the activation of intestinal symptoms as well, while deciding on the treatment of the patients with enteropathic arthritis.

In a systematic review and metanalysis in which 13 studies evaluating the effects of NSAID's use on intestinal findings in patients with IBD; It has been shown that NSAID's do not cause intestinal exacerbation in both $\mathrm{CH}$ and $\mathrm{UC} .^{3}$ AntiTNF agents; It has proven to be highly effective in the treatment of IBD patients who are steroiddependent or refractory to conventional therapy and in extraintestinal findings. Anti-TNF agents are effective in both axial and peripheral joint involvement in patients with entropathic arthritis. Infliximab, adalimumab and certalizumab are indicated in the treatment of remission induction and remission maintenance in Crohn's disease. ${ }^{4}$ In ulcerative colitis, infliximab, adalimumab and golimumab are indicated for remission induction and remission maintenance therapy. ${ }^{5}$ Thus the choice and the configuration of the treatment are important for the course of the disease. The wellbeing can be achieved in both the articular and the intestinal symptoms of the patients thanks to the common medications to be used in the treatment.

\section{Conflict of Interests}

Authors declare that there are none.

\section{Acknowledgment}

This study has been presented in $17^{\text {th }}$ Uludag Internal Medicine National Winter Congress, $6^{\text {th }}$ Bursa Family Medicine Association National Congress, $11^{\text {th }}$ Uludag Internal Medicine Nursing Congress, 5-7 March 2021, Bursa, Turkey.

\section{References}

1. Peluso $\mathrm{R}$, Di Minno MN, Iervolino S, Manguso F, Tramontano G, Ambrosino P, Esposito C, Scalera A, Castiglione F, Scarpa R. Enteropathic spondyloarthritis: from diagnosis to treatment. Clin Dev Immunol. 2013;2013:631408. doi: 10.1155/2013/631408.

2. Beslek A, Onen F, Birlik M, Akarsu M, Akar S, Sari I, Gurler O, Akpinar H, Manisali M, Akkoc N. Prevalence of spondyloarthritis in Turkish patients with inflammatory bowel disease. Rheumatol Int. 2009 Jun;29(8):955-7. doi: 10.1007/s00296-008-0811-5.

3. Moninuola O O, Milligan W, Lochhead P, Khalili $\mathrm{H}$. Systematic review with meta-analysis: association between acetaminophen and nonsteroidal antiinflammatory drugs (NSAIDs) and risk of Crohn's disease and ulcerative colitis exacerbation. Aliment Pharmacol Ther. 2018 Jun;47(11):1428-39. doi: 10.1111/ apt.14606.

4. Veauthier B, Hornecker JR. Crohn's Disease: Diagnosis and management. Am Fam Physician. 2018 Dec 1;98(11):661-9.

5. Ungaro R, Mehandru S, Allen PB, Peyrin-Biroulet L, Colombel JF. Ulcerative colitis. Lancet. 2017 Apr 29;389(10080):1756-1770. doi: 10.1016/S01406736(16)32126-2. 